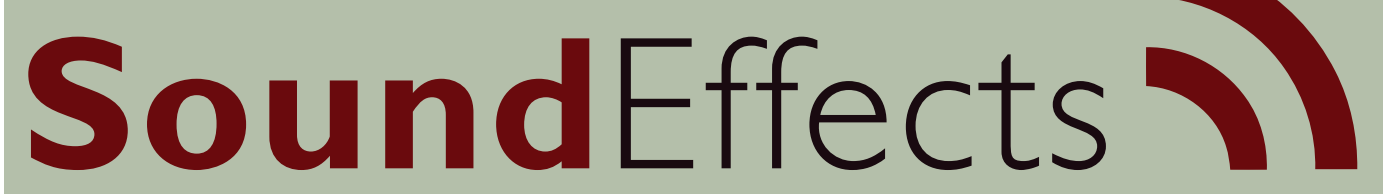

An Interdisciplinary Journal of Sound and Sound Experience

\title{
Caroline Bassett
}

\section{Everything that arises does not converge:}

the audiovisual and the incomplete

Dr. Caroline Bassett,

Senior Lecturer in Media and Film Studies

University of Sussex

C.Bassett@sussex.ac.uk 


\begin{abstract}
Computational culture is often explored through discourses of completion and in terms of the complete and this bias extends to accounts exploring new media and the senses, where it may be expressed in terms of priority as an assertion of the 'proper' ratio of the senses. In response this article explores the aesthetics of the incomplete, the latter understood as an intrinsic element of new media culture rather than an exception. It begins with claims that new media are essentially (ontologically) sonic, reading this in contrast to the New Aesthetic and visual glitch and focussing on the consequences of the NA's fierce concentration on the visual. This frames a consideration of sonic glitch in a public sound art work in which audiovisual technologies are reprogrammed to break down language - and open up a form of common space. The article concludes that the incomplete can be productively viewed as an intrinsic part of the contemporary digital formation: something ontologically given, but also something invoked, worked with and used in different ways. An issue for sound art, in this context, is to find ways to intervene in the incomplete rather than let it become (another) site for the reflection and activation of existing industrial values.
\end{abstract}

\title{
Everything that arises does not converge: the audiovisual and the incomplete
}

In a recent performance the thereminist and roboticist Sarah Angliss worked on donated sounds captured by volunteers as MP3 and other audio files (Angliss, 2013). Voices, noises, the sounds of a tattoo parlour, bells, cars - all were reworked between the fields of a musical instrument played without touch, where proximity is enough, and where the fingers of the performer seem to pick at the air itself. In Angliss' hands the sounds of the everyday dissolved, broke up and were remade; the result was fragmentation, unexpected life, the promise of something, nothing complete. The theremin is a retro instrument, invented and largely discarded in the twentieth century, but this performance seemed to capture something essential about forms of contemporary experience, not least because of its entanglement with surveillance; ${ }^{1}$ and this unfinished introduction to Angliss provides an atmosphere for this piece...

Contemporary public spaces of many kinds, the various grounds of everyday life, are transformed, through pervasive computerisation, into multilayered assemblages of various spaces, times, materials and densities - many unseen or unheard, some experienced differentially (that is, in personalised ways), some hard to experience directly at all. In these spaces tightly channelled data streams (audio, visual, audiovisual) augment and reorganise an already highly mediatised general envi- 
ronment in which public media of many kinds are ubiquitous. These developments, of course, are under active investigation. For instance, in some of my own earlier work I have explored the division of sensory attention, asking how technologically enabled channelling accelerates the personalised productivity accepted - or struggled against - as a key responsibility in digital capitalism (Bassett, 2009). A striking feature of many of these investigations, and something evident in work on digital transformation in general, is its tendency to focus, not only on trajectories, but on endings, outcomes, completions - on trajectories' ends. Consider the end of the narrative, the dominance of the database, the priority of the game, terminal identity (or its terminal dissolution), the focus on the end user, for instance; all presume end points and all are discourses that fit under the banner of convergence. The teleological orientation common in discourses around media technological innovation contributes to this focus, which is very marked in medium centric writing where the influence of Kittler and his arguments for the computer as the culmination and end point of all media are powerful (Kittler, 1999).

The demand for completion and for the complete is, of course, not confined to theory but is apparent in emerging digital culture. It is an operational imperative of digital capitalism (the delivery of full surveillance, full information, the fully responsible citizen), one that finds cultural resonances in the desire for, for instance, absolute fictional realism, full friendship sets, the totally encompassing view, the enveloping and fully personalised information service. When digitally fuelled transformations of everyday life are explored specifically in terms of the senses - as transformations in the ratio of the senses - a related bias towards completion is often evident and may be articulated through questions concerning 'what completes in what'; sound in vision, vision in sound? Priority engages with issues of completion.

So, the bias towards completion can initially be understood to arise as a response to real-world formations under investigation and as a habitual critical orientation, a habit of thinking that might obscure other aspects of emerging constellations. With the goal of disrupting this habit, in this chapter the focus is on the incomplete. Everything that arises - even in a world that is pervasively mediatised as a consequence of widespread computerisation - does not converge. The complete has as a counterweight the incomplete, an element that remains neglected and undertheorised in explorations of contemporary constellations. More than an element, in fact, if that term implies that incomplete formations are shards floating in a landscape; the incomplete is dynamic. What the computational enacts is fragmentation as well as coalescence. The incomplete is ubiquitous in computational cultures.

Where is it found? Consider the technological discontinuities that are part of an informational architecture - glitches, breaks, stutters, slowdowns. These are exceptions to the smooth running of a system, although they are also expected 
and common exceptions (routine damage limitation operations). Then there are the dropped connections, sudden window switches, the document interrupted, the file left open and abandoned - all human-initiated screen practices. These operate in the wider physical environment as semi-exchanges, half-finished and reversed interactions, in unfinished traffic between data streams in different modes (audio/ visual/audiovisual), so that the incomplete operation is an intrinsic part of the physical environments into which these screens and devices are embedded and of which they increasingly form a substantial part. The computationally dense environment is full of discontinuous computer operations, unfinished architectures and incomplete practices.

These switches, stops, changes, stutters, glitches and those that are less marked or abrupt can be traced in relation to the senses, indeed can operate modal shifts; an image is half absorbed and attention returns to sound. The words that make a sentence are half said out loud and vanish, reappear as something that may be viewed, but not audited somewhere else, or fade entirely - the sense they might have been intended to make is never completed, neither in what used to be accepted as an everyday 'here and now' nor in any single individual's horizon.

These sensory shifts and discontinuities may be patterned, expressing something of the contemporary ratio of the senses - and the latter are always normative and contingent. Thus, a contrast can be drawn between contemporary formations and earlier analyses of fragmentation and totality that explored the division of the senses and the alignments they articulated. Notably, in his essay 'Walking in the City' de Certeau famously set bodies and narratives, walking and silence, the felt and the heard, against a regime operating through the scopic and the architectural; the latter were properties of domination and were continuous, while the former, understood as modes of resistance taken up through various sense registers, were fragmentary (de Certeau, 1984). In contrast here vision as well as sound is explored through the incomplete, and the latter is not explored as a mode of resistance (although it might be put to use in many ways), but as an intrinsic part of differently ordered constellations. Old alignments and (what were previously understood as) 'natural' affinities have to be reconsidered.

The incomplete is hard to grasp and model; terminal comprehension of the incomplete would, after all, be a contradiction in terms, and although the visualisation of the not quite there is an alluring project to contemplate undertaking, the incomplete is not easily captured through frontal assault (for instance by the tools and methods of big data mapping). The obvious obstacles to visualisation here may be a pointer to methods of enquiry. They suggest that the incomplete, habitually the reversed out, rather than sketched in section of any map, is easier to trace in some registers than in others. It may be more productive to feel for, rather than seek to view the outline of, an incomplete formation, or to listen in rather than look out 
for, and to seek a glimpse or indirect view, rather than the fixed picture. And it may also be fruitful to explore the seams between various senses, to investigate multisensory channelling processes and points of sensory crossover, moments of transition where what arises might often tend to disintegrate or recombine.

All the above may be undertaken as speculations in theory, but may also be explored through a consideration of new media art of various kinds. For some, for instance Mark Hansen (Dyson, 2009), new media art is the privileged site through which digital futures may be glimpsed or prefigured - a view that suggests the degree to which artistic speculation might itself partake in the trajectories of completion outlined above, and that also underscores issues of intention; if digital media art prefigures particular kinds of future, then what role does intention or commitment play in this?

These issues are followed up below in an enquiry that focusses on digital aesthetics. First through noting issues of sensory priority and considering a sonic ontology of new media. Second via a brief account of the New Aesthetic (NA), exploring its relentless focus on the visual and the visual glitch. This frames a return to sound via consideration of art working with glossolalia and its refused, but ongoing, promise of language. Finally connections and disjunctions between the visual glitch (and the observational aesthetic) and the glossolaliac stutter, both dealing in various forms of the incomplete, but in terms that might be more or less ecologically computational, are drawn out.

\section{Priority?}

The composer Michel Chion, writing of the audiovisiogenic effects of mainstream cinema, noted that the sound is completed in the image (Chion, 2000). This aligns with the priority accorded to the visual in Western culture generally (Howes, 2006) and in twentieth-century media audiovisual technologies (film, television) and media industries (promotional culture) dominated by spectacle in particular. This prioritisation relates to sound's phenomenal tendencies, but is also a cultural reading: literally a Western viewpoint which is/was then accelerated by visual technologies of the screen (sound studies itself is a restitution of the sonic emerging as a critical response to the dominance of this perspective). Chion's sense of priority as organised within and amplified by a technological apparatus, the narrative machine of cinema, can be drawn upon to consider issues of priority (sense ratio and completion) in a world that has become saturated with media, and that is heavily mediatised. We are coming to live, not quite 'in the movies', as Kittler and Pynchon prophesised we would (see Pynchon, 2000 in: Kittler, 1997), but rather in a world of which digital technologies form a substantial part. 
In these contexts the triumph of the scopic world view, the extension of the priority of the visual, has been expected - the Baudrillardian version of this predicted the world as full spectacle, as screen became world became screen, for instance. This situation has not arrived. Arguably in recent times there has been, in contrast, a certain reprioritisation of the sonic dimension of everyday life, and in these contexts some theorists have found it useful to enquire whether the priority of vision might be questioned and its cultural status reassessed (e.g. Bull, 2005; Bassett, 2011). Symptoms and players in this shift in priorities are late-twentieth/twenty-firstcentury mobile devices (Walkmans, iPods and on) that have enabled the rearrangement of the sonic/visual economies within which their users move, and that have been influential far more broadly in changing modes of everyday life. Increasingly multimodal today, these nonetheless began with 'completion in sound' rather than 'completion in vision' in mind (they began as devices designed primarily for audio; uses such as texting and image capture came later) and, at least early on, thus redirected attention towards the sonic (as film arguably did for the image in earlier decades). The key point, however, is not the archaeology of these kinds of devices, it is that they provide modes of sonic control and direction that operate in tension with sound's own phenomenal tendencies to absorb, connect and migrate (Howes, 2006, p. 41) and also to join; as Conner notes, sound lacks the separating qualities of vision (Connor, 2004). If a new kind of priority is being accorded to sound, it is thus partly because the sonic environment has become controllable in new ways and at new points; mobile digital technologies, enabling new forms of human engagement with the production of sound and soundscapes, make this clear. It is, moreover, evident that these technologised/channelled/privatised soundscapes can offer more personal control than similar visual devices do. Personalised sonic bubbles have coproduced, co-performed, co-declared and co-created the responsible individual self. The world, it may be said, may be assembled or retuned in the ear, rather than the eye, of the user.

Exploring some of these formations Jonathan Sterne has argued convincingly that, partly as a consequence of digital audio technologies, hearing itself has become understood as increasingly technological in computational times (Sterne, 2006 and elsewhere). And this, in turn, might focus attention on how sound acts and operates over what a sound might come to 'mean' socially (as a discursive social construction). Similarly, discussions of priority (in relation to the ratio of the senses) relying on underpinning assertions of (sonic or visual) ontology, enabling particular definitions of the phenomenal qualities of sound and vision to be asserted, also rely on the technological organisation of these sense data streams. Moreover, what results, an ordering of the senses, is not only classificatory, but is also, as a classification, operational. 


\section{Sonic ontology}

If discussions of the sonic, including those exploring its putative reprioritisation in relation to the image, currently often begin with the consequences of technology and its reorganisations, does this imply that sound's phenomenal, even ontological, properties are neglected? Working with sound art the critical theorist Frances Dyson makes a rather different case. Essentially she argues that if sound has become increasingly technological, this is because new media technology has sonic qualities (Dyson, 2009). Dyson thus not only reprioritises sound over vision in relation to new media technologies, but invokes sound to redefine new media art and its aesthetics - and to make a case for a digital aesthetic founded in the sonic. The immersive capacities computational technologies offer, by way, in earlier times, of the interface and PC screen (as the minimal equipment for immersive interaction), virtual reality rigs, and now through ecological media, each of which produce different forms of embodiment, are key in this argument. New media is defined in terms of immersion, in contrast to definitions based on interaction or on code 'itself', and these are ontological claims; new media may, says Dyson, produce an 'immersive experience that is ontologically grounded' $(2009, \mathrm{p}$. 3). Immersion, which might produce a particular form of atmosphere (the term is Dyson's), aligns far more closely with the sonic (which fuses, bleeds, leaks, might translate into touch) than with vision, the latter conventionally characterised by separation and the distanced view. In these terms a new media archaeology can be traced - this moves from the immersive aesthetic of the 1990s and early VR works responding to first life in the screen, through Web 2.0, and on out to environmental media as itself offering new forms of immersion. Dyson's discussion of digital artist Char Davies' journey from Osmose, a breathable VR environment/installation, shown at Serious Games (London) and elsewhere and widely recognised in the 1990s as either a response to or the ne plus ultra of a digital sublime based on virtualisation, to more recent work, developed on Davies' land in Quebec, traces out this kind of archaeology. Davies' later work, unfinished and apparently non-computational, faint, interrupted and barely there, points to an emerging aesthetic - perhaps a post-technological aesthetic for new media - that responds to a pervasively mediatised environment.

Thus, in contradistinction to Sterne's account, which traces out the technologisation of the senses - particularly in relation to hearing - for Dyson the point is to expose sonic qualities (always) already intrinsic to new media, if not yet fully realised or understood. Thus, it is possible to argue that new media art is sonic - or put the other way around, that it is successful to the degree that it foregrounds the sonic qualities intrinsic to the material it works with; qualities that may travel, or be transposed, so that they are present in what were previously understood to be non-sonic objects. 
Since Dyson follows Hansen (see above) in arguing that new media art can operate in advance of the more general instantiation of the materials of which it is made, this exposure is aptly undertaken through the production of sound art. And, given that for Dyson digital media art can presage and prefigure future formations, when she argues that "new media art ... representing the pinnacle of digital media ... seems not to aspire to the conditions of media ... but ... to the conditions of sound' (Dyson, 2009, p. 3), she is making a case not only for new media art, but for everyday life in computational times. New media art can reveal new media as a sonic medium ${ }^{2}-$ and can thus explain that reprioritisation of the sonic dimension of everyday life that has come about with the proliferation of new media discussed above.

\section{Here are some things: the New Aesthetic}

A markedly different exploration of new media aesthetics, one that once again defines itself through technology, but this time is image based, is being undertaken via the NA. This engages with what Bruce Sterling has termed the eruption of the digital' into the physical environment (Sterling, 2012) by inviting humans to 'see like a digital device. ${ }^{3}$ The NA deals in saturation; it is what happens when the dense pressure of digital material all around, operating in many channels, builds up and breaks into the physical environment. It is therefore concerned with glitch, overflow and exhaust; the most iconic image in the collection, Benjamin Norman's Pixel Pour (2008), depicts a street pipe out of which flow 'pixels'.

The NA began as a 'modest' collection of Tumblir images assembled by James Bridle (Bridle, 2012) and emerged from one particularly digitally intensive zone (London's Shoreditch, long a software design and creative media hub) before mapping onto another when it was taken up at the SXSW conference in the US, where its significance as a marker of the circumstances of digital saturation was recognised. Debates around the NA now circulate around interconnected global industry hubs (e.g. Wired), tech and art blogs and amongst software and code studies theorists, in relation to critical writing on software studies, and by those debating objectoriented ontologies (0OO) (see below). The NA thus has proximate virtual address and a relation to physical places, operating between the grain of the computational and the material of the physical and thereby enacting the very situation it sets out to observe.

What it does not have is a programme. The NA is a collection of images found in a particular milieu. It is not avant-garde, it does not seek to shock or disrupt, but simply to collect, to note the noteworthy or unusual or striking and to recirculate it. It rejects the metaphorical ${ }^{4}$ and the futurological in favour of capturing some things from an existing constellation; those things it likes. Bruce Sterling, amongst others, has noted that this is both the basis of its significance - it is honest about 
a particular formation and its values - and also of its limitations. It is, he says, 'a gaudy, network-assembled heap ... made of digitized jackstraws that were swept up by a generational sensibility' (Sterling, 2012).

The NA collection makes a virtue of the unexpected reversal in perspective that makes visible computational materials generally unseen, or that provides what is (apparently) the viewpoint from the machine. Reversing out one form of the expected it thus introduces a new one, making banal the fact of digital saturation and the operations that this entails. This kind of perspective shift is often given through the glitch, which, apart from issuing a knowing invitation (you in the know, know why this is amusing because you understand the operation that has apparently misfired), apparently offers a form of accidental, but 'real' access to something else's viewpoint.

But of course there are glitches and 'glitches', and for all its attachment to the found object (as the foundation for the collection) what is found is not simply found, but has been 'made'; it is a representation of glitch as well as a glitch capture. The NA, in other words, is drawing on and contributing to a developing aesthetic through which 'glitch' is represented and to which it is becoming central. David Berry gets at this when he points to the significance of the often invoked image effects of the now surpassed limits of the pixel in the NA collections (Berry, 2012). This makes clear the degree to which these images deal with fictions of the computational - albeit in this case fictions that are based on computational histories and cultures rather than on other forms of retro-tech nostalgia. And in this way, of course, they deal in a new form of realism.

By contrast, what is 'really real' is the relationship between the NA and the digital industry. The NA is a design aesthetic already embedded in the outputs and expressing the industrial logics and discourses of the new media industries. And it uses this industry's materials - human and non-human - as its matter. This is why the NA aesthetic, not avant-garde, but simply industrial, is, as Ian Bogost has put it, 'not surprising, but expected'.

\section{After all, the artists now wield the same data access APIs, mapping middleware, and computer vision systems as the corporations. In some cases, the artists are the cor- porations. (Bogost, 2012b)}

The NA expresses the environmentalisation of (a particular kind of) corporate culture, the eruption of the digital industrial into the world of the everyday. This complete identification tempers claims that it offers glimpses of a radically different perspective - a view from the point of view of software or code, or the computational solely. 


\section{Not going further - the only computational?}

The NA has attracted the attention of various theorists working with object-orientated ontology/philosophy, the project of which is to direct attention away from explorations of events and phenomena as they are filtered through (human) sensory experience and discourse and turn towards things themselves. The intention is to understand the world from the point of view of the many things that exist within it that are not human. None of these are accessible directly by humans - and the tendency of things, it is argued, is to withdraw. Approaching requires tactics including speculation (e.g. via a poetics or a poetics of speculative realism) and the examination of the exhaust that things extrude - hence the interest in what spills over, in the entrails of things. Bogost argues, in peculiarly muscular, but also interestingly sonic terms, that the role of the 000 investigator is to make things hum:

To amplify the black noise of objects to make the resonant frequencies of the stuffs inside them hum in credibly satisfying ways. Our job is to write the speculative fictions of these processes, of their unit operations. Our job is to get our hands dirty with grease, juice, gunpowder, and gypsum. Our job is to go where everyone has gone before, but where few have bothered to linger. (Bogost, 2012b)

As Berry (2012) notes, for some the NA is or could be an aesthetic for 000, whilst others refuse the connection. There are some obvious resonances between them: notably the NA's preoccupation with digital things, which it does not seek to approach through discourse or (human) interpretation, nor through any form of commitment (once again this is not an avant-garde). In contrast to the potential for 'cool' linguistic and literary creativity that Alan Liu discerns in the swarming human activity that co-constitutes networks (see Liu, 2013), the NA's 'cool' emanates from the nonhuman objects it gathers, which are to some extent independent of these human entanglements and might be said to have their own relations. Thus, for Borenstein the NA is important to object-oriented approaches precisely because it is striving towards a fundamentally new way of imagining the relations between things in the world' (Borenstein, 2012).

A very different position is taken by Ian Bogost who argues that the NA, as an approach to understanding the contemporary world, is sadly lacking (2012a). The key to his objection is the limited viewpoint a reading of the contemporary world in terms of interaction between humans and computers provides. Here be humans, and here be computers, says Bogost, but where are the other objects in the world, those objects that are more interesting than both and at least as significant, if not more so ${ }^{6}$ As the futurists did with the car, but without even the recompense of a manifesto, he says, the NA is self-limiting - and this is due to its bad choice of things. 
Because it stops at the computational and focusses on the human-computer interface, it does not map onto or offer much to the 000 project.

An obvious rejoinder, of course, is that the NA specifically sets out to gather computational things. But given that the NA is operating at a moment when the computational becomes ecological, when it is clearer than ever before that relationships between humans and computers do also entail other things - when what is being discussed after all is an irruption of the digital into the physical - then it seems to me that Bogost's objections are justified.

Glancing back momentarily to Dyson's arguments for a new media aesthetic based on an immersive principle developed through an analysis of the sonic and her discussion of the trajectory of new media artist Char Davies' work - from closed virtual reality to the open circuits of the unfinished/incomplete paths inscribed into the earth - the difference between these two aesthetics is very clear. The difference between the ecological and non-ecological approach is bound up in the NA's visual prioritisation. The computationally centric view of the world, granted by the NA, is one granted through and by the visual; it is - and this is to be expected, given where it comes from industrially, an aesthetic made on the screen. To the complaint that the NA is only computational can thus be added the complaint that it is in the end only representational - it mediates as much as operates. Exposed here are the limitations of a way of grappling with the world that completes itself in the audiovisual image, rather than in the narrowly computational; but in both cases the issue is material.

The lack of ambition that Bogost discerns in the NA, which makes it less interesting for the 000 project, is thus also pertinent here in thinking about distinctions between sonic and visual responses to and in new media. It is striking that the 000 project itself is often defined in terms of the sonic, as in the injunction above to listen for the distant and necessarily incomplete 'hum' of faraway things.

In many ways the NA un-manifesto is, despite its refusal to make demands, very imposing. Above all its collector aesthetic, binding up the principle of found object with the distancing effect of the list, makes what is proffered up as evidence difficult to question - it is this that conceals the NA's industrial rather than technological roots and its representational bias. It is ironic that the NA claims to modestly collect rather than seeking to narrate or account for - let alone argue for or against - a particular aesthetic of the digital, since it has produced a narration. These images are being proffered up as canonical elements of 'what the new digital reality is'. Valorising a certain collecting aesthetic, relying on an appeal to the ontological whilst being based on an industrial logic, and talking of the collision of two whole worlds - 'physical' and 'virtual' - whilst confining itself to an interaction space within audiovisual terrains, it produces a canon. In doing so, it provides itself with a tale and perhaps, despite its intentions, offers an explanation. 


\section{Sound (art) that makes space?}

The visual glitch, established as central to the NA, as it reports on new media, stands in contrast to Dyson's reading of new media as an immersive process - and provides a different working through of the incomplete within the contemporary formation. The final sections of this piece bring elements from each together in a consideration of the sonic glitch via a sound art piece that deals explicitly both in the glitch and in the incomplete.

smSage, a public sound art installation designed to create contingent public spaces in city streets, was produced by Borland and Redfern in 2007. It set out to comment on the extension of visual surveillance systems to include sonic elements. The work was avowedly a response to the development of surveillance cameras that crossed audiovisual barriers and began to 'speak back' (Borland and Redfern, 2007); however, clear genealogies can also be traced out in the tradition of sound art, notably via works such as Alvin Lucier's I am Sitting in a Room, explored at length by Seth Kim-Cohen (2009, p. 190).

Consciously playing with the channelling of audio and visual material through new media technologies, smSage works at the seam of the audiovisual. It consists of a mounted surveillance camera casing containing equipment to rebroadcast text messages solicited via broadcast appeal and Bluetooth from passers-by. These contributed voices, SMS contributions characterised by their pared down grammar and elliptical phrasing and therefore already operating at the edge of coherence, are broadcast clearly once, are repeated, and degrade at each repetition. The result is described as a 'mad murmur' (Borland and Redfern, 2007) proliferating across the street, producing a sonically curated space of a particular kind.

The move perhaps, drawing on Dyson's terminology, is from channel into atmosphere, both because there is a shift from the audiovisual into the environment, and also because atmosphere might be a useful way to consider what language offers in this work. To begin with the latter, Borland and Redfern's 'mad murmur' is not entirely speech or 'non-speech'. It is speech interrupted or glitched, so that what is voiced as speech does not deliver language, but instead can be understood in terms of glossolalia. The latter is defined by de Certeau (1996) as a 'trompe-l'oreille, just like a trompe-l'oeil, a semblance of language that can be fabricated when one knows its phonetic rules' (1996, p. 29). Glossolalia plays with language. It 'speaks for the sake of speaking', retaining something of the appeal language makes to another, but at the same time is ready to 'slip the snares of meaning'. This kind of giving voice, says de Certeau, may 'fill a space of enunciation with polyphonic chatter' (1996, p. 29). Glossolalia may in this way be understood as a means through which a particular kind of sonically defined space, whose principle is the incomplete, is made. In the case of smSage, a sheltering murmur, slipping from language but remaining in voice, 
sounding out something close to what de Certeau calls 'the tattoo of the vocal', can slide on from something experienced as sound to something felt more like a vibration, a sympathetic resonance or a form of sonic solidarity that is at once human and machinic and that might produce a common space. ${ }^{7}$

This kind of approach is distinguished from Dyson's in that it does not rely on an ontological affinity between digital technology and the sonic, but rather plays with how a certain kind of sonic atmosphere might be engineered. In this sound art work (as in Angliss' theremin experiment with which this piece began) technology's expected channelling effects, and the expected priority of various data streams that comes with it, are reversed. The surveillance instrument (the camera-like device) takes (in) a message and reworks it, but does not freeze it and render it comprehensible and complete, but fragments it into something that, wriggling out of the constraints of meaning but containing voice's felt appeal to the other, disperses out across an environment where it forms a temporary acoustic 'hood'. This might be more than a reversal of modes, however; it may also be dealing in, grappling with, new ways in which the digital physical comes into being - here as an incomplete space performed in and through sound. What is also suggested in this piece is that both the audio and the visual are unfinished in each other and reach out beyond the narrow bounds of the world as we experience it through technologised vision of the mediatised eye. One suggestion here is that the hierarchical completion of the audio in the visual that Chion observed in cinema - and explored as an example of the domination of a particular sense ratio - may productively not be reversed, but confounded, in artwork exploring contemporary constellations.

A final question then, unanswered here in this avowedly incomplete account, concerns the degree to which it might be feasible to move from a discussion of the incomplete as visual and sonic glitch to a consideration of the glitch and/as part of a narrative experience - perhaps towards something that can be termed narrativish. I have always found it intriguing that Barthes, famous for demanding endings, also said, 'meaning is not found at the end of a narrative but runs across it' (Barthes, 1977, p. 79).

\section{Bibliography}

Angliss, S. (2013). Performance at SoundDAY, Brighton. Also Performed on Radio Reverb, 25 June 2013. Accessed on: http://www.sarahangliss.com/

Barthes, R. (1977). Image, Music, Text. New York: Hill and Wang.

Bassett, C. (2009). Up the Garden Path. Second Nature, 2, 42-61.

Bassett, C. (2011). Twittering Machines: Antinoise and other tricks of the ear. Differences, summerfall 2011, 276-300.

Bassett, C. (2012). Digital Media. Review Article. Year's Work in Critical Theory (YWCT), 20(1). Accessed on: http://www.le.ac.uk/engassoc/publications/ywcct.html 
Behrendt, F. (2008). Texting and Calling Public Spheres: Mobile Phones, Sound Art, and Habermas. In: Hartmann, M., Rössler, P., \& Höflich, J.R. (Eds.), After the Mobile Phone? Social Changes and the Development of Mobile Communication (pp. 35-54). Berlin: Frank and Timme.

Berry, D. (2012). What is the New Aesthetic. Stunlaw. Accessed June 2013 on: http://stunlaw.blogspot. co.uk/2012/04/what-is-new-aesthetic.html

Bogost, I. (2012a). Alien Phenomenology: or What It's Like to Be a Thing. University of Minnesota Press.

Bogost, I. (2012b). The New Aesthetic Needs to Get Weirder. The Atlantic. Accessed on: http://www. theatlantic.com/technology/archive/2012/04/the-new-aesthetic-needs-to-getweirder/255838/

Borenstein, G. (2012). What It's like to be a 21st Century Thing. Essay in the Creators Project. In Response to Bruce Sterling's 'Essay on the New Aesthetic'. Accessed June 2013 on: http://thecreatorsproject.vice.com/blog/in-response-to-bruce-sterlings-essay-on-the-new-aesthetic

Bridle, J. (2012). Booktwo.org. 15 March 2012. Accessed June 2013 on: http://booktwo.org/notebook/ sxaesthetic/

Bridle, J. (n.d.). New Aesthetic. Accessed June 2013 on: http://new-aesthetic.tumblr.com/about

Bull, M. (2005). No Dead Air! The iPod and the Culture of Mobile Listening. Journal of Leisure Studies, 24(4), 343-355.

Chion, M. (2000). Audio-Vision and Sound. In: Kruth, P., \& Stobart, H. (Eds.), Sound (pp. 201-229). Cambridge: Cambridge University Press.

Connor, S. (2004). Sound and the Self. In: Smith, M.M. (Ed.), Hearing History: A Reader (pp. 54-59). Georgia: Georgia University Press.

Creators Project (2012). In Response to Bruce Sterling's 'Essay on the New Aesthetic'. Accessed June 2013 on: http://thecreatorsproject.vice.com/blog/in-response-to-bruce-sterlings-essay-onthe-newaesthetic

Davies, C. (1995). Osmose. Digital artwork. Accessed June 2013 on: http://www.immersence.com/ biography/bio_100.html

De Certeau, M. (1984). The Practice of Everyday Life. Berkeley: California University Press.

De Certeau, M. (1996). Vocal Utopias: Glossolalias. The New Erudition, 56(Autumn), 29-47.

Dyson, F. (2009). Sounding New Media: Immersion and Embodiment in the Arts and Culture. Berkeley: University of California Press.

Fuller, M. (2008). Software Studies/A lexicon. London: MIT.

Hayles, N. K. (2009). RFID: Human Agency and Meaning in Information-Intensive Environments. Theory, Culture \& Society, 26(2-3), 47-72.

Howes, D. (2006). Sensual Relations: Engaging the Senses in Culture and Social Theory. Michigan: Michigan University Press.

Kim-Cohen, S. (2009). In the Blink of an Ear: Toward a Non-Cochlear Sonic Art. London: Continuum.

Kittler, F. (1997). Media and Drugs in Pynchon's Second World War (trans. Wutz and Winthrop Young). In: Tabbi, J., \& Wutz, M. (Eds.), Reading Matters: Narratives in the New Media Economy (pp. 157-172). Ithaca and London: Cornell University Press.

Kittler, F. (1999). Gramophone, Film, Typewriter. Stanford, CA: Stanford University Press.

Liu, A. (2011). Where is Cultural Criticism in the Digital Humanities. Paper presented at the panel on 'The History and Future of the Digital Humanities', Modern Language Association convention, Los Angeles, 7 January. Accessed June 2013 on: http://liu.english.ucsb.edu/where-is-culturalcriticism-in-the-digital-humanities/Humanities

Liu, A. (2013). From Reading to Social Computing, Literary Studies in the Digital Age. MLACommons. Accessed June 2013 on: http://dlsanthology.commons.mla.org/from-reading-to-socialcomputing/ [DOI: 10.1632/lsda.2013.2]

Plant, S. (1997). Zeroes and Ones. New York: Doubleday

Pynchon, T. (2000). Gravity's Rainbow. London: Vintage.

Redfern, T., \& Borland, R. (2007). smSage. New York City. 
Schwartz, H. (2004). On Noise. In: Smith, M.M. (Ed.), Hearing History: A Reader (pp. 51-54). Georgia: Georgia University Press.

Sterling, B. (2012). Beyond the Beyond. Wired. Accessed June 2013 on: http://www.wired.com/ beyond_the_beyond/2012/04/an-essay-on-the-new-aesthetic/

Sterne, J. (2006). The mp3 as Cultural Artefact. New Media and Society, 8(5): 825-842.

\section{Notes}

1 N. Katherine Hayles reminds us that the theremin, as listening device, has always been entangled in surveillance politics; citing Glinsky (2000) she tells the story of the embedding of a device designed by Leon Theremin inside the US Embassy in Moscow during the Cold War (Hayles, 2009, p. 48).

2 There are intriguing parallels here with ontological claims for new media made in a different decade. Notably in the 1990s Sadie Plant argued that technology (generally socially coded masculine) was essentially feminine.

3 The phrase appears on a flyer for an SXSW conference session.

4 There may be odd parallels here with the non-metaphorical credo of Chinese new documentary, with its fierce and absolute insistence that it is only capturing what is there.

5 Similar protests were voiced against Davies' Osmose when it was first launched.

6 This produces a list of 'things that might have been included'. See Bogost (2012a) on lists and alien phenomenology, and David Berry on the 000 propensity for 'thing lists' with sleepinducing qualities (Berry, 2012).

7 Frauke Behrendt has explored smSage via Habermas's consideration of small publics, suggesting it might produce a hermeneutic bridge to link SMS micro-sites/micro-publics (2008). I agree with this, but staying with the voice as sound, rather than moving towards speech as communication, also seems productive here - particularly because it directs attention into space (see also Bassett, 2011). 